\title{
More on modality effects and the lack of them in the absence of sound
}

\author{
SUSAN KARP MANNING \\ Hunter College and the Graduate Center of the City University of New York, New York, New York
}

Following the work of Nairne and McNabb (1985), some previously unpublished data on recency and suffix effects in the visual and tactual modalities are presented. These data and the further analysis of some previously published data clarify the complicated picture of research in this area. The implications of the presence of a new "modality effect," involving the tactual and visual modalities, are discussed for the various theories proposed to explain recency, suffix effects, and modality effects.

Recency may be defined as the superiority of recall of the last presented items over the middle items in serial recall. The modality effect has been defined as the superior recall due to greater recency for items presented in the auditory than in the visual modality (Crowder \& Morton, 1969).

In a recent paper, Nairne and $\mathrm{McNabb}$ (1985) have purported to find a new modality effect. They have found that performance is better at the end of a recalled sequence for tactual than for visual stimuli. They also have shown tactual recency.

Using Nairne and McNabb's (1985) paper as a springboard, it seems useful to reinterpret some previous work from my laboratory, as well as to present some unpublished work that perhaps was done before it fit the theoretical framework of the time. As with the findings by Nairne and $\mathrm{McNabb}$, our findings provide new information relevant to explanations of recency and modality effects.

What, specifically, did Nairne and McNabb report in their paper? In Experiment 1, subjects in the visual condition looked at sequences of wooden blocks containing $1,2,3$, or 4 pegs, whereas subjects in the tactual condition touched the same configurations that were blocked from vision. In Experiment 2, subjects received sequences of the numbers $1,2,3$, and 4 presented on a CRT. In one condition (visual), they read them silently, whereas in the other condition (tactual), they pressed a finger corresponding to the numbers on the CRT screen against their thumb. Recall in both experiments was serial and written. In Experiment 1, subjects wrote down the number of pegs presented in the displays. In Experiment 2, the actual numbers on the CRT were to be recalled.

In both experiments, Nairne and McNabb (1985) reported significantly greater recency for the tactual con-

\footnotetext{
Support was provided for the previously unpublished work reported here and some of the published work by Grant No. BNS-76-18,763 from the National Science Foundation to the author. Please address reprint requests to Susan Karp Manning, Department of Psychology, Hunter College, 695 Park Avenue, New York, NY 10021.
}

ditions than for the visual conditions. They interpreted these modality effects as being indicative of new difficulties for the various theories that have been proposed to handle recency and modality effects.

To give a brief history of these theories: Crowder and Morton (1969) explained recency and the standard modality effect in terms of long-lasting auditory sensory traces, which contained additional information. These lasting traces allowed longer rehearsal of the final item and thus a recall advantage leading to recency for auditory stimuli. Since the visual traces were too short-lived to be useful, no recency was present for these stimuli.

More recent findings involving visual stimuli have cast doubts on this theory. Specifically, Campbell and Dodd (1980), among others, reported recency for lipread stimuli, whereas Shand and Klima (1981), using congenitally deaf subjects, reported similar recency for American Sign Language signs.

What then about the modality effect reported by Nairne and $\mathrm{McNabb}$ (1985)? Oddly enough, early results in my laboratory on recency and suffix effects in the tactual modality came from what might be called a tactual modality effect, in that memory for items presented tactually was superior to that for items presented visually. Specifically, we (Manning, Pasquali, \& Smith, 1975) used an anticipation procedure with five- or six-unit repeating patterns of lateralized lights or taps on the left or right palm, and found that tactually presented stimuli led to recall performance that was superior to recall of visually presented stimuli. This tactual superiority was similar to that reported by Handel and Buffardi $(1968,1969)$ with vibratory stimuli presented laterally on the hands and lights lateralized on a board. In both our work and that of Handel and Buffardi, subjects had to learn repeating patterns of left and right stimuli.

In another experiment, also reported in Manning et al. (1975), we found that tactually presented lateralized stimuli led to faster asymptotic probability matching than did visually presented lateralized stimuli.

Puzzled by these unexpected modality effects when visual superiority was expected (see Freides, 1974), we 
looked at whether various cognitive variables might be interacting with presentation modality. Finding none, we hypothesized that the modality effect might be due to a more "perceptual" type of processing. Following this view and the hypotheses of several researchers that the tactual modality generates long-lasting sensory traces (e.g., Gilson \& Baddeley, 1969; Watkins \& Watkins, 1974), we attempted to test this hypothesis.

Three studies were performed in which subjects were asked for serial recall of lateralized lights or taps presented visually or tactually (Manning, 1978). In the control condition of these studies, a tactual modality effect appeared. Additionally, using a Peterson and Peterson (1959) paradigm, as with the auditory modality that was also thought to lead to lasting sensory traces, tactual stimuli were shown to be significantly more susceptible to various types of interference than were visual stimuli. Thus, we hypothesized that we might have some evidence for tactual sensory traces.

However (and this is the important finding with respect to recency), unlike with auditorily presented alphanumeric stimuli, there was neither a real recency effect, nor even a relative advantage at the end of the sequence for tactually as compared with visually presented stimuli in the control condition of these studies. Our lack of major recency effects is consistent with the results of Watkins and Watkins (1974), who found only a small amount of recency in the control conditions of a suffix study using tactual stimuli. However, these researchers did not make visual comparisons.

Other work in this laboratory has shown that superiority of tactual over visual modality is usually, but not always, present in studies using binary lateralized stimuli (see Manning, 1978). In the cases where no tactual advantage exists, performance is usually virtually equal for the two modalities. This is surprising in terms of the usual visual performance.

Further relevant work using this paradigm compared sequences of tactual, visual, and auditory binary stimuli (the auditory stimuli were lateralized tones) with respect to recency as well as suffix effects (Manning, 1977). In this experiment, recency clearly was not present in any of the modalities. The data from the control conditions are shown in Table 1. This finding is consistent with the previous work for the tactual and visual modalities. The auditory findings are similar to those of Foreit (1976), who also did not find recency for recall of tones.

Additional work in this laboratory has compared the tactual and visual modalities. Two studies, performed and

\section{Table 1}

Serial Position Curves for the Control Conditions of Tactual, Visual, and Auditory Sequences

\begin{tabular}{lcccccccc}
\hline Modality & 1 & 2 & 3 & 4 & 5 & 6 & 7 & 8 \\
\hline Tactual & .75 & 1.62 & 1.96 & 1.67 & 2.58 & 2.92 & 3.08 & 3.04 \\
Visual & .88 & 1.29 & 1.58 & 1.92 & 2.00 & 2.58 & 3.25 & 4.12 \\
Auditory & .83 & 1.17 & 1.33 & .92 & 1.79 & 2.42 & 2.46 & 2.38 \\
\hline
\end{tabular}

Note-Scores represent mean number of errors at each position. The maximum number correct is 8 .
Table 2

Control Conditions for Tactual Presentation on Optacon

\begin{tabular}{ccccccc}
\hline Serial Position & 1 & 2 & 3 & 4 & 5 & 6 \\
\hline Experiment 1 & 2.55 & 2.39 & 1.80 & 1.64 & 1.11 & 1.36 \\
Experiment 2 & 2.25 & 2.67 & 2.03 & 1.86 & 1.78 & 1.86 \\
\hline
\end{tabular}

Note-Maximum number correct is 6 .

cited by Nairne and McNabb (1985), compared recall for stimuli drawn on the palm of the hand with the end of a pen (tactual condition) with that for stimuli drawn against a white card, also with the end of a pen (visual condition; Manning, 1980). In no condition was a mark made with the pen.

Using these stimuli, visual performance was significantly better than tactual performance in both experiments. In addition, recency was not present in either modality. Finally, there was no relative advantage for tactual stimuli at the end of the sequence. In fact, if anything, there was a slight relative advantage for the visual modality.

A final set of studies from this laboratory bears directly on this issue. We compared visual and tactual performance on the Optacon and published the visual results (Manning \& Gmuer, 1985). The Optacon is a reading aid for the blind that presents tactual stimuli to the finger. The display is similar to a dot matrix (generated by moving pins) and produces a stimulus similar to the Times Square News Display, with stimuli moving from right to left (see Manning \& Gmuer, 1985). The Optacon also has a visual display that monitors the tactual impulses and produces an analogous moving dot matrix.

Subjects in both visual and tactual conditions were asked to recall sequences of letters serially. The tactual control conditions for two unpublished experiments are produced in Table 2.

Visual superiority was enormous because learning to use the tactual component of the Optacon is difficult for both blind and sighted subjects. Our sighted Hunter College population was given only a small amount of training. Nonetheless, neither the published visual nor the unpublished tactual conditions produced recency effects.

The question then is how our data add to the literature on recency and modality effects. First, it should be noted that the Nairne and McNabb (1985) results are unusual for tactual stimuli in two ways. First, they are the only results that seem to show recency in this modality. Second, they appear to be part of the small group of tactual tasks for which performance is better or the same as in the visual modality (e.g., Handel \& Buffardi, 1968, 1969; Manning, 1977, 1978; Manning et al., 1975).

With respect to the finding of recency in Nairne and McNabb's (1985) studies, we agree with them that their results cannot be due to sound or aspects of sound, as might have been consistent with views such as those of Crowder and Morton (1968).

Additionally, these stimuli are not "changing state," that is, they do not change over time. Campbell and Dodd (1980), among others, have explained auditory recency 
and the effects with lipread stimuli and American Sign Language signs in these terms.

In fact, the results of Manning (1980) and the Optacon data reported here use changing-state tactual stimuli that do not show recency. We believe that our results along with those of Manning (1986) and Crowder (1985) have now eliminated the changing-state view of recency as the source of visual recency. Nairne and $\mathrm{McNabb}$ have joined us in completing the job for tactual stimuli. We have found changing-state tactual stimuli that dc not produce recency; they have found static tactual stimuli that do.

As to what really is the source of recency and modality effects, some sort of distinctiveness of final item view seems to fit a variety of data. For example, a recent study in this laboratory (Manning, 1986) has shown that a distinctive item in a list (a color name in a list of adjectives unrelated to each other), if it is located at the end of the list, produces almost perfect recall performance and is virtually immune to suffix effects. However, if this type of distinctive item can appear at any location, recency is reduced and suffix effects appear.

However, it has yet to be determined why final items in sequences of lipread stimuli, American Sign Language signs, and the tactual stimuli in the Nairne and McNabb (1985) study are especially distinctive, whereas final items are not for other visual and tactual stimuli.

As to the tactual modality effect, we are back where we were in 1975. We cannot explain the adeptness for tactual tasks relative to that for visual tasks. We have eliminated sensory traces as a likely mechanism for the special adeptness, at least if recency is required as an indicator that sensory traces are an aid in recall (Manning, 1977, 1978). However, it is still possible that sensory traces may operate to a greater degree in the specific tasks producing tactual adeptness while still not producing recency. However, this does not seem to be a likely mechanism. What the aspects are of a tactual task that produce this adeptness appear at this point to be as elusive as the causes of recency.

\section{REFERENCES}

Campbell, R., \& Dodd, B. (1980). Hearing by eye. Quarterly Journal of Experimental Psychology, 32, 85-99.

Crowder, R. G. (in press). Auditory and temporal factors in the modality effect. Journal of Experimental Psychology: Human Learning \& Cognition.

Crowder, R. G., \& MorTon, J. (1969). Precategorical acoustic storage (PAS). Perception \& Psychophysics, 5, 365-373.

ForeIt, K. G. (1976). Short-lived auditory memory for pitch. Perception \& Psychophysics, 19, 368-378.

FreIDES, D. (1974). Human information processing and sensory modality. Psychological Bulletin, 81, 284-310.

Gilson, E. Q., \& BADDEleY, A. (1969). Tactile short-term memory. Quarterly Journal of Experimental Psychology, 21, 180-184.

HANDEL, S., \& BufFardi, L. (1968). Pattern perception: Integrating information presented in two modalities. Science, 162, 1026-1028.

HANDEL, S., \& BUFFARDI, L. (1969). Using several modalities to perceive one temporal pattern. Quarterly Journal of Experimental Psychology, 21, 256-266.

MANNING, S. K. (1977, November). Suffix effects on non-verbal tactual, visual and auditory sequences. Paper presented at the meeting of the Psychonomic Society, Washington, DC.

MANNING, S. K. (1978). The effects of interpolated interference on tactual and visual short-term memory. American Journal of Psychology, 91, 445-459.

Manning, S. K. (1980). Tactual and visual alphanumeric suffix effects. Quarterly Journal of Experimental Psychology, 32, 257-267.

MaNNING, S. K. (1986). Recall and suffix effects for "distinctive" stimuli. Manuscript submitted for publication.

ManNing, S. K., \& GMUER, B. A. (1985). Visual suffix effects on the Optacon: A test of changing state, primary, linguistic, and attentional theories. Bulletin of the Psychonomic Society, 23, 1-4.

Manning, S. K., Pasquali, P. E., \& Smith, C. A. (1975). Effects of visual and tactual stimulus presentation on learning two choice patterned and semirandom sequences. Journal of Experimental Psychology: Human Learning \& Memory, 1, 736-744.

NAIRNE, J. S., \& MCNABB, W. L. (1985). More modality effects in the absence of sound. Journal of Experimental Psychology: Learning, Memory \& Cognition, 11, 596-604.

Peterson, L. R., \& Peterson, M. J. (1959). Short-term retention of individual items. Journal of Experimental Psychology, 58, 193-198.

ShaND, M. A., \& Kuma, E. S. (1981). Nonauditory suffix effects in congenitally deaf signers of American Sign Language. Journal of Experimental Psychology: Human Learning \& Memory, 7, 464-474.

Watkins, M. J., \& WatKINS, O. C. (1974). A tactile suffix effect. Memory \& Cognition, 2, 176-180. 